\title{
Antimalarial and $\beta$-hematin formation inhibitory activities of chromone derivatives
}

\author{
Chirattikan Maicheen ${ }^{\mathrm{a}}$, Jiraporn Ungwitayatorn ${ }^{\mathrm{b}, *}$ \\ ${ }^{\text {a }}$ Faculty of Pharmacy, Huachiew Chalermprakiet University, Samut Prakarn 10540 Thailand \\ b Faculty of Pharmacy, Mahidol University, Bangkok 10400 Thailand
}

*Corresponding author, e-mail: jiraporn.ung@mahidol.ac.th

Received 5 Feb 2019

Accepted 24 May 2019

\begin{abstract}
A series of chromone compounds were evaluated as new potential antimalarial agents using in vitro antimalarial activity assay. The most potent compound 36 with an $\mathrm{IC}_{50}$ of $0.95 \mu \mathrm{M}$ was shown to be more potent than primaquine and tafenoquine ( $\mathrm{IC}_{50} 2.41$ and $1.95 \mu \mathrm{M}$, respectively). $\beta$-Hematin formation inhibitory activity test and stoichiometry determination have also been performed to investigate the preliminary mechanism of antimalarial activity of the studied compounds. Compounds $23-28$ ( IC $_{50} 1.41,1.76,2.30,2.54,4.60$, and $3.69 \mu \mathrm{M}$, respectively) displayed greater $\beta$-hematin formation inhibitory activity than chloroquine, dihydroartemisinin, and mefloquine (IC ${ }_{50}$ 25.04, 18.04, $15.78 \mu \mathrm{M}$, respectively). Compounds $3,4,23,24,27,36,38$, and 43 showed high potency in both antimalarial and $\beta$-hematin formation assays. Job's plots indicated that compounds showing high $\beta$-hematin formation inhibitory activity formed stable complexes with the same stoichiometric ratio of chromone:heme $=1: 2$ as chloroquine. This study opens up the possibility of development of chromone derivatives as new antimalarials targeting $\beta$-hematin formation.
\end{abstract}

KEYWORDS: chromone derivatives, antimalarial activity, $\beta$-hematin formation inhibitory activity

\section{INTRODUCTION}

Despite the efforts to eradicate and control malaria, this disease remains the major causes of ailment and mortality, threatening and killing millions of people each year ${ }^{1,2}$. The causative agents of malaria in human are five different species of Plasmodium, i.e., Plasmodium falciparum, $P$. vivax, $P$ malariae, $P$. ovale, and $P$. knowlesi. Among these, $P$. falciparum is the most virulent parasite with high mortality rate. Malaria has become more difficult to treat because of the increasing prevalence of multi-drug resistance of malaria parasites and unavailability of a successful vaccine ${ }^{3}$. Discovery and design of new chemical compounds acting on novel targets are necessary to overcome the emergence of resistance to the clinical currently used drugs.

During the intraerythrocytic stages of malaria infection, the parasite consumes hemoglobin of the infected red blood cell to serve as amino acids sources. This process of hemoglobin degradation occurs within the acidic food vacuole of the parasite and subsequently toxic free heme is released. The plasmodium parasites detoxify the free heme by converting into a malaria pigment known as hemozoin $^{4,5}$. Since hemozoin formation is essential for the survival of these parasites, inhibiting hemozoin formation leads to parasite death. X-ray crystallography and spectroscopic analyses indicate that hemozoin has the same structure as the synthetic analog, $\beta$-hematin ${ }^{6,7}$. $\beta$-Hematin is a heme dimer formed via reciprocal covalent bonds between carboxylic acid groups on the protoporphyrin-IX ring and the iron atoms of two heme molecules. These dimers interact via hydrogen bonds to produce crystals of hemozoin. The hemozoin formation pathway is unique to the malarial parasite, therefore, it serves as an attractive target for the new antimalarial drug discovery.

Several types of antimalarial drugs have been reported to exhibit antimalarial activity by enhancing free heme toxicity through the inhibition of $\beta$ hematin formation. The quinoline antimalarials, i.e., chloroquine, quinine, and amodiaquine were found to form complexes with dimeric hematin and preventing the formation of $\beta$-hematin ${ }^{8-11}$. 9Anilinoacridine derivatives have been reported to target at two different sites within the malaria parasite, i.e., DNA topoisomerase II and $\beta$-hematin formation $^{12}$. Xanthone derivatives, a novel antimalarial agent, have been found to exert their activity by complexation with heme and inhibition 




Fig. 1 General structure of chromone compounds.

of $\beta$-hematin formation ${ }^{13,14}$.

The in vitro studies have shown that flavonoid compounds, natural phenyl substituted chromones, exhibited remarkable antimalarial activity ${ }^{15-18}$. For example, dehydrosilybin and 8-(1;1)-DMAkaempferide showed a direct antimalarial activity on several multidrug-resistant strains of cultureadapted $P$. falciparum ${ }^{16}$ and the diprenylated flavonoids showed a notable antimalarial activity ${ }^{18}$. The aim of this study was to investigate the in vitro antimalarial activity against $P$. falciparum of compounds in chromone series (general structures as shown in Fig. 1). $\beta$-Hematin formation inhibitory activity test and stoichiometry determination have also been performed in order to explore the preliminary mechanism of antimalarial activity of compounds in this series.

\section{MATERIALS AND METHODS}

The chromone compounds used in this study were available from previous works and were prepared as described in the report of those studies ${ }^{19,20}$.

\section{In vitro antimalarial activity assay}

The evaluation of antimalarial activity against $P$. falciparum using microculture radioisotope assay was performed by the Bioassay Laboratory, National Center of Genetic Engineering and Biotechnology (BIOTEC), Thailand. In vitro cultivation of $P$. falciparum (K1, multi-drug resistant strain) was performed according to the method previously described by Trager et $\mathrm{al}^{21}$. The parasite was cultivated in RPMI-1640 medium containing 25 mM HEPES (N-2-hydroxyethylpiperazine- $\mathrm{N}^{\prime}$-2ethanesulfonic acid), $25 \mathrm{mM} \mathrm{NaHCO}{ }_{3}, 10 \%$ heatactivated human serum, and $3 \%$ erythrocytes. The culture was incubated at $37^{\circ} \mathrm{C}$ in a humidified incubator with $3 \% \mathrm{CO}_{2}$-enriched atmosphere $(3 \%$ $\mathrm{CO}_{2}, 17 \% \mathrm{O}_{2}$ and $80 \% \mathrm{~N}_{2}$ ). Daily passaged to fresh medium containing erythrocyte in order to maintain parasite growth was performed. Prior to the assay, the parasite at an early ring-stage growth was collected and prepared to a parasite mixture of $1 \%$ parasitemia in $1.5 \%$ erythrocytes.

The protocol for the assay was a modification of the method described by Desjardins et $\mathrm{al}^{22}$. The uptake of $\left[{ }^{3} \mathrm{H}\right]$ hypoxanthine by parasites was used as an indicator of viability. The assay was performed in duplicate wells in 96-well plate. In each well, 200 $\mu \mathrm{l}$ of parasite mixture (1\% parasitemia and 1.5\% erythrocytes) was pre-exposed with $25 \mu l$ of the medium containing a test sample dissolved in $1 \%$ DMSO for 24 hours. Medium $(25 \mu \mathrm{l})$ containing $0.5 \mu \mathrm{Ci}\left[{ }^{3} \mathrm{H}\right]$-hypoxanthine (Perkin Elmer, USA) was added to each well. The plates were incubated for an additional 24 hours. Levels of incorporated radioactive labeled hypoxanthine indicating parasite growth were determined using the TopCount NXT Microplate Scintillation and Luminescence Counters (Perkin Elmer, USA). All chromone derivatives were tested at concentration of $10 \mu \mathrm{g} / \mathrm{ml}$ (except for compound $36,1 \mu \mathrm{g} / \mathrm{ml}$ was used due to the solubility limitation of this compound). Dihydroartemisinin and mefloquine (purchased from Tokyo chemical industry, Japan) were used as the positive control. The negative control was $0.1 \%$ DMSO. The percentage of parasite inhibition was calculated from the signal count per minute of treated $\left(\mathrm{CPM}_{\mathrm{T}}\right)$ and untreated samples $\left(\mathrm{CPM}_{U}\right)$ using the following equation:

$$
\text { Parasite inhibition }(\%)=\left(1-\frac{\mathrm{CPM}_{\mathrm{T}}}{\mathrm{CPM}_{\mathrm{U}}}\right) \times 100 \text {. }
$$

If $\%$ parasite inhibition was $<50 \%$, the activity was reported as inactive, and as active if $\geqslant 50 \%$.

All compounds reported as active were selected for the $\mathrm{IC}_{50}$ (the concentration of sample required to inhibit 50\% parasite growth) determination. The $\mathrm{IC}_{50}$ was derived from the plot between six concentrations $(0.0412,0.123,0.370,1.11,3.33$, and $10.00 \mu \mathrm{M})$ and \% parasite inhibition using curvefitting method with SOFTMax Pro software (Molecular Devices, USA). The $\mathrm{IC}_{50}$ values reported herein were the average values of the three separated experiments.

\section{$\beta$-Hematin formation inhibition assay}

The $\beta$-hematin formation inhibitory activity was determined based on the method of Baelmans et $\mathrm{al}^{23}$. Forty two chromone compounds were tested at the concentration of $30 \mu \mathrm{M}$. Hemin chloride (purchased from Tokyo chemical industry, Japan) was used 
as source of heme in this study. A solution containing $50 \mu \mathrm{l}$ of $4 \mathrm{mM}$ hemin chloride and $50 \mu \mathrm{l}$ of chromone compound dissolved in DMSO was distributed in a microcentrifuge tube. $\beta$-Hematin formation was initiated by adding $100 \mu \mathrm{l}$ of $0.2 \mathrm{M}$ acetate buffer $\mathrm{pH}$ 4.4. The mixture was incubated at $37^{\circ} \mathrm{C}$ for 48 hours to allow completion of the reaction. After centrifuging at $4000 \mathrm{~g}$ for 15 minutes, the supernatant was discarded. The pellets (the generated $\beta$-hematin appeared as dark brown pellet) were washed 3 times with DMSO ( $300 \mu l)$ to remove the unreacted hemin chloride from $\beta$-hematin which was insoluble in DMSO. The pellets were dissolved in $0.2 \mathrm{~N} \mathrm{NaOH}(200 \mu \mathrm{l})$ and the obtained solubilized aggregates (free heme in $\mathrm{NaOH}$ ) were prepared for spectroscopic quantification. The absorbance was recorded at $386 \mathrm{~nm}$ using UV-microplate reader. The amount of free monomeric heme was calculated from the standard curve of hemin chloride. The results were expressed as percentage of inhibition of $\beta$-hematin formation using the following formula:

$$
\text { Inhibition }(\%)=\left(1-\frac{[\text { Heme }]_{\text {drug }}}{[\text { Heme }]_{\text {control }}}\right) \times 100
$$

where $[\text { Heme }]_{\text {drug }}=$ amount of heme in sample and $[\text { Heme }]_{\text {control }}=$ amount of heme in control.

Chloroquine diphosphate, dihydroartemisinin, and mefloquine $\mathrm{HCl}$ (all purchased from Tokyo chemical industry, Japan) were used as positive control and DMSO as a negative control. The assay was performed in triplicate in each of the three separated experiments. The twelve most potent chromone compounds as well as chloroquine diphosphate, dihydroartemisinin, and mefloquine $\mathrm{HCl}$ were determined for the $\mathrm{IC}_{50}$ values. The $\mathrm{IC}_{50}$ value was calculated from the $\log$ dose-response curve using Graphpad Prism 5. The reported $\mathrm{IC}_{50}$ values were the average values of the three independent experiments.

\section{Drug-heme interaction assay}

An aqueous DMSO (40\% v/v) solution of $10 \mu \mathrm{M}$ hemin chloride $(\mathrm{pH}$ 7.4) was freshly prepared by mixing $25 \mu \mathrm{l}$ of $4 \mathrm{mM}$ hemin chloride in $0.1 \mathrm{M}$ $\mathrm{NaOH}$ with $4 \mathrm{ml}$ of DMSO and $1 \mathrm{ml}$ of $0.02 \mathrm{M}$ sodium phosphate buffer ( $\mathrm{pH}$ 6.0). The solution was adjusted to the volume of $10 \mathrm{ml}$ with deionized water (hemin chloride was monomeric form in this solution). Solutions of chromone compounds, dihydroartemisinin and chloroquine diphosphate were prepared as described for hemin chloride.

Interaction of chromone compounds with hemin chloride was investigated by monitoring their effect on the absorption profile of hemin chloride. The spectral changes were determined by a continuous variation technique (Job's plot). Solutions containing 14 molar ratios of chromone compounds and hemin chloride were prepared as follows: compounds $28,38,42$, and dihydroartemisinin, 0:1, 1:9, 1:4, 3:7, 2:3, 7:9, 1:1, 52:47, 9:7, 3:2, 7:3, 4:1, 9:1, and 1:0; compounds $3,4,23-27,43$, chloroquine, and mefloquine, $0: 1$, $1: 9,1: 4,3: 7,13: 27,7: 13,3: 5,2: 3,1: 1,3: 2,7: 3$, $4: 1,9: 1$, and $1: 0$; compound $36,0: 1,1: 9,7: 33$, $1: 4,1: 3,11: 29,3: 7,2: 3,1: 1,3: 2,7: 3,4: 1,9: 1$, and $1: 0$. The final combined concentration of hemin chloride and chromone compound in the mixture was $10 \mu \mathrm{M}$. Absorbance spectra between 200 and $700 \mathrm{~nm}$ were recorded by a Shimadzu UV-Visible spectrophotometer. The absorbance change was calculated using the absorbance value from each molar ratio at the maximum wavelength $400 \mathrm{~nm}$. Plots were constructed between the absorbance change versus the molar ratio of compound and heme.

\section{RESULTS AND DISCUSSION}

\section{In vitro antimalarial activity against $P$. falciparum}

In our previous study, we have reported the antimalarial activity against $P$ falciparum (K1, multidrug resistant strain) of twenty-one chromone compounds using microculture radioisotope assay ${ }^{20}$. In this study, a series of more than 21 compounds were tested using the same method. Table 1 summarizes the antimalarial activity and $\mathrm{IC}_{50}$ values of the studied compounds whose structures were classified as 3-unsubstituted and 3-substituted chromone derivatives. Compounds with inhibitory activity higher than $50 \%$ were subjected to $\mathrm{IC}_{50}$ determination. The three most potent compounds, 34, 36 and 39, belonging to 3 -substituted series, displayed the $\mathrm{IC}_{50} 3.82,0.95$, and $4.87 \mu \mathrm{M}$, respectively. Preliminary structure-activity relationship could be deduced from the results that most of the 3substituted chromone compounds (compounds containing $\mathrm{R}_{2} \mathrm{CO}$ at position 3 of the chromone nucleus) showed the higher potency ( $\mathrm{IC}_{50} 0.95-12.40$ $\mu \mathrm{M}$, Table 1) than the 3-unsubstituted derivatives $\left(\mathrm{IC}_{50} 9.15-19.66 \mu \mathrm{M}\right)$. Comparison of the activity for compounds with same $\mathrm{OH}$ and $\mathrm{R}_{2}$ substituted patterns showed that the 3 -substituted compounds displayed better activity than the corresponding 3-unsubstituted compounds, for examples, compounds 39 (IC $\left._{50} 4.87 \mu \mathrm{M}\right)$ versus $11\left(\mathrm{IC}_{50} 14.69\right.$ 
Table 1 Structures and antimalarial activity (\% inhibition and $\mathrm{IC}_{50}(\mu \mathrm{M})$ ) of the 3-unsubstituted and 3-substituted chromones tested at the concentration $10 \mu \mathrm{g} / \mathrm{ml}$.

\begin{tabular}{|c|c|c|c|c|c|c|c|c|c|}
\hline \multicolumn{5}{|c|}{ 3-Unsubstituted chromones } & \multicolumn{5}{|c|}{ 3-Substituted chromones } \\
\hline $\mathrm{Cp}$ & Structure & $\mathrm{R}_{2}$ & $\%$ Inhibit & $\mathrm{IC}_{50}$ & Cp & Structure & $\mathrm{R}_{2}$ & $\%$ Inhibit & $\mathrm{IC}_{50}$ \\
\hline 1 & & Phenyl & -3.82 & - & $\begin{array}{l}32 \\
33 \\
34\end{array}$ & & $\begin{array}{l}3^{\prime}-\left(\mathrm{CF}_{3}\right) \text {-Phenyl } \\
3^{\prime} \text {-(Cl)-Phenyl } \\
3^{\prime}-\left(\mathrm{OCH}_{3}\right) \text {-Phenyl }\end{array}$ & $\begin{array}{l}8.40^{\mathrm{a}} \\
24.20 \\
98.38\end{array}$ & $\begin{array}{c}- \\
- \\
3.82\end{array}$ \\
\hline $\begin{array}{l}3 \\
4\end{array}$ & & $\begin{array}{l}\text { Benzyl } \\
\text { Phenyl }\end{array}$ & $\begin{array}{l}96.90^{\mathrm{a}} \\
71.90^{\mathrm{a}}\end{array}$ & $\begin{array}{r}9.43 \\
19.66\end{array}$ & $\begin{array}{l}35 \\
36 \\
37 \\
\end{array}$ & & $\begin{array}{l}4^{\prime} \text {-(F)-Phenyl } \\
4^{\prime}-\left(\mathrm{NO}_{2}\right) \text {-Phenyl } \\
4^{\prime}-\left(\mathrm{OCH}_{3}\right) \text {-Phenyl }\end{array}$ & $\begin{array}{l}7.50^{\mathrm{a}} \\
77.50^{\mathrm{a}, \mathrm{b}} \\
66.19\end{array}$ & $\begin{array}{l}- \\
0.95 \\
9.32 \\
\end{array}$ \\
\hline $\begin{array}{l}5 \\
11 \\
12 \\
13 \\
14 \\
15 \\
16\end{array}$ & & $\begin{array}{l}\mathrm{CH}_{3} \\
3^{\prime}-\left(\mathrm{CF}_{3}\right) \text {-Phenyl } \\
4^{\prime} \text {-(F)-Phenyl } \\
3^{\prime}, 5^{\prime} \text {-(diNO }{ }_{2} \text { )-Phenyl } \\
3^{\prime} \text {-(Cl)-Phenyl } \\
3^{\prime}, 4^{\prime} \text {-(diCl)-Phenyl } \\
4^{\prime} \text {-(t-butyl)-Phenyl }\end{array}$ & $\begin{array}{r}-0.69 \\
56.80 \\
17.49 \\
95.62 \\
23.18 \\
6.51 \\
82.30^{\mathrm{a}}\end{array}$ & $\begin{array}{c}- \\
14.69 \\
- \\
10.30 \\
- \\
- \\
11.41\end{array}$ & $\begin{array}{l}38 \\
39 \\
40 \\
41 \\
42 \\
43 \\
44\end{array}$ & & $\begin{array}{l}3^{\prime}, 4^{\prime} \text {-(diF)-Phenyl } \\
3^{\prime}-\left(\mathrm{CF}_{3}\right) \text {-Phenyl } \\
3^{\prime} \text {-(Cl)-Phenyl } \\
\left.3^{\prime} \text {-(OCH }\right) \text {-Phenyl } \\
4^{\prime} \text {-(F)-Phenyl } \\
4^{\prime}-\left(\mathrm{NO}_{2}\right) \text {-Phenyl } \\
\left.4^{\prime} \text {-( } \mathrm{OCH}_{3}\right) \text {-Phenyl }\end{array}$ & $\begin{array}{l}65.10^{\mathrm{a}} \\
98.70^{\mathrm{a}} \\
23.40 \\
-1.50 \\
-0.08 \\
71.30^{\mathrm{a}} \\
93.17\end{array}$ & $\begin{array}{c}12.40 \\
4.87 \\
- \\
- \\
- \\
9.85 \\
11.73\end{array}$ \\
\hline 17 & & $3^{\prime}-\left(\mathrm{CF}_{3}\right)$-Phenyl & $84.10^{\mathrm{a}}$ & 11.07 & 45 & & 4'-(t-butyl)-Phenyl & $98.50^{\mathrm{a}}$ & 5.46 \\
\hline $\begin{array}{l}18 \\
19 \\
20\end{array}$ & & $\begin{array}{l}4^{\prime} \text {-(F)-Phenyl } \\
3^{\prime}, 4^{\prime} \text {-(diF)-Phenyl } \\
4^{\prime} \text {-(t-butyl)-Phenyl }\end{array}$ & $\begin{array}{l}37.50^{\mathrm{a}} \\
24.30^{\mathrm{a}} \\
95.20^{\mathrm{a}}\end{array}$ & $\begin{array}{l}- \\
- \\
9.15\end{array}$ & $\begin{array}{l}46 \\
47\end{array}$ & & $\begin{array}{l}3^{\prime}-\left(\mathrm{OCH}_{3}\right) \text {-Phenyl } \\
4^{\prime}-\left(\mathrm{NO}_{2}\right) \text {-Phenyl }\end{array}$ & $\begin{array}{l}65.93 \\
99.50^{\mathrm{a}}\end{array}$ & $\begin{array}{r}10.47 \\
5.91\end{array}$ \\
\hline $\begin{array}{l}22 \\
23 \\
24\end{array}$ & & $\begin{array}{l}\left.3^{\prime}, 5^{\prime} \text {-(diNO }{ }_{2}\right) \text {-Phenyl } \\
3^{\prime} \text {-(Cl)-Phenyl } \\
3^{\prime}, 4^{\prime} \text {-(diCl)-Phenyl }\end{array}$ & $\begin{array}{l}-2.81 \\
76.20^{\mathrm{a}} \\
99.50^{\mathrm{a}}\end{array}$ & $\begin{array}{c}- \\
13.83 \\
11.25\end{array}$ & 48 & & $4^{\prime}$-(t-butyl)-Phenyl & 89.07 & 9.33 \\
\hline $\begin{array}{l}25 \\
26 \\
\end{array}$ & & $\begin{array}{l}4^{\prime}-\left(\mathrm{OCH}_{3}\right) \text {-Phenyl } \\
3^{\prime} \text { - }\left(\mathrm{OCH}_{3}\right) \text {-Phenyl }\end{array}$ & $\begin{array}{l}27.50^{\mathrm{a}} \\
28.00^{\mathrm{a}}\end{array}$ & $\begin{array}{l}- \\
- \\
\end{array}$ & 50 & & $3^{\prime}-\left(\mathrm{OCH}_{3}\right)$-Phenyl & 97.24 & 6.07 \\
\hline 27 & & $3^{\prime}-\left(\mathrm{OCH}_{3}\right)$-Phenyl & $68.00^{\mathrm{a}}$ & 13.23 & & & & & \\
\hline $\begin{array}{l}28 \\
29 \\
31\end{array}$ & & $\begin{array}{l}3^{\prime} \text {-(Cl)-Phenyl } \\
4^{\prime} \text {-(F)-Phenyl } \\
4^{\prime} \text {-(t-butyl)-Phenyl }\end{array}$ & $\begin{array}{r}39.52 \\
49.12 \\
8.40\end{array}$ & $\begin{array}{l}- \\
- \\
-\end{array}$ & & $\begin{array}{l}\text { Chloroquine } \\
\text { Dihydroartem } \\
\text { Mefloquine }\end{array}$ & & & $\begin{array}{c}0.42 \\
2.2 \times 10^{-3} \\
5.7 \times 10^{-2}\end{array}$ \\
\hline 49 & & $3^{\prime}-\left(\mathrm{OCH}_{3}\right)$-Phenyl & $84.70^{\mathrm{a}}$ & 13.94 & & $\begin{array}{l}\text { Primaquine } \\
\text { Tafenoquine }\end{array}$ & & & $\begin{array}{l}2.41 \\
1.95\end{array}$ \\
\hline
\end{tabular}

${ }^{\mathrm{a}}$ results obtained from the previous study ${ }^{20}$; ${ }^{\mathrm{b}}$ activity tested at $1 \mu \mathrm{g} / \mathrm{ml} ; \mathrm{Cp}=$ compound,

$\mu \mathrm{M}), 45\left(\mathrm{IC}_{50} 5.46 \mu \mathrm{M}\right)$ versus $16\left(\mathrm{IC}_{50} 11.41 \mu \mathrm{M}\right)$, 46 (IC $_{50} 10.47 \mu \mathrm{M}$ ) versus 26 (inactive), 48 (IC $_{50}$

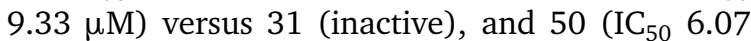
$\mu \mathrm{M})$ versus $49\left(\mathrm{IC}_{50} 13.94 \mu \mathrm{M}\right)$. With the exception of compounds 40 and 14, both showed a similar low-potency.

\section{Inhibition of $\beta$-hematin formation}

To preliminarily determine the possible the mechanism of antimalarial activity of the chromone compounds, the in vitro $\beta$-hematin formation inhibitory activity assay was performed. This assay closely paralleled the hemozoin formation within the parasite food vacuole. In this assay, heme (hemin chloride) was allowed to form $\beta$-hematin under acidic conditions (0.2 $\mathrm{M}$ acetate buffer, $\mathrm{pH} 4.4)$. In the presence of an inhibitor, the complexation of the inhibitor and heme led to the inhibition of $\beta$-hematin formation.
The uncomplexed heme was allowed to generate $\beta$-hematin which was consequently converted into free monomeric heme. The amount of free heme was measured spectrophotometrically at $386 \mathrm{~nm}$. The more the inhibitor-heme complex formed, the less the absorbance of free heme detected.

Forty-two chromone compounds were tested for their ability to inhibit $\beta$-hematin formation and the results obtained are summarized in Table 2 . Compounds with more than $45 \%$ inhibition were considered as potent inhibitor (i.e., compounds 3, 4, 23$28,36,38,42$, and 43 ) and were subjected to $\mathrm{IC}_{50}$ determination. The six most potent compounds, 23-28 ( IC $_{50}$ values 1.41, 1.76, 2.30, 2.54, 4.60, and $3.69 \mu \mathrm{M}$, respectively) showed higher inhibitory activity than chloroquine, dihydroartemisinin, and mefloquine $\left(\mathrm{IC}_{50}\right.$ 25.04, 18.04, and $15.78 \mu \mathrm{M}$, respectively). In contrast to antimalarial activ- 
Table 2 The $\beta$-hematin formation inhibitory activity of the 3-unsubstituted and 3-substituted chromone derivatives tested at the concentration $30 \mu \mathrm{M}$.

\begin{tabular}{|c|c|c|}
\hline \multicolumn{3}{|c|}{ 3-Unsubstituted chromones } \\
\hline Compound & $\%$ Inhibition & $\mathrm{IC}_{50}(\mu \mathrm{M})$ \\
\hline 1 & $14.55 \pm 0.41$ & - \\
\hline 3 & $46.03 \pm 0.99$ & $30.56 \pm 0.39$ \\
\hline 4 & $45.00 \pm 0.79$ & $27.72 \pm 0.71$ \\
\hline 5 & $16.11 \pm 0.38$ & - \\
\hline 11 & $37.19 \pm 0.36$ & - \\
\hline 12 & $34.88 \pm 1.01$ & - \\
\hline 13 & $16.19 \pm 0.36$ & - \\
\hline 14 & $36.40 \pm 0.71$ & - \\
\hline 15 & $14.18 \pm 0.86$ & - \\
\hline 16 & $13.07 \pm 0.20$ & - \\
\hline 17 & $18.91 \pm 0.72$ & - \\
\hline 18 & $16.39 \pm 0.52$ & - \\
\hline 19 & $25.64 \pm 0.30$ & - \\
\hline 20 & $20.46 \pm 0.33$ & - \\
\hline 22 & $23.92 \pm 0.97$ & - \\
\hline 23 & $83.60 \pm 0.21$ & $1.41 \pm 0.21$ \\
\hline 24 & $81.95 \pm 0.60$ & $1.76 \pm 0.11$ \\
\hline 25 & $81.84 \pm 1.06$ & $2.30 \pm 0.17$ \\
\hline 26 & $76.98 \pm 0.35$ & $2.54 \pm 0.13$ \\
\hline 27 & $89.62 \pm 0.28$ & $4.60 \pm 0.15$ \\
\hline 28 & $84.70 \pm 0.42$ & $3.69 \pm 0.01$ \\
\hline 29 & $33.70 \pm 0.26$ & - \\
\hline 31 & $38.43 \pm 0.20$ & - \\
\hline 49 & $6.93 \pm 0.16$ & - \\
\hline \multicolumn{3}{|c|}{ 3-Substituted chromones } \\
\hline Compound & $\%$ Inhibition & $\mathrm{IC}_{50}(\mu \mathrm{M})$ \\
\hline 32 & $38.37 \pm 0.23$ & - \\
\hline 33 & $31.34 \pm 0.23$ & - \\
\hline 34 & $38.42 \pm 0.35$ & - \\
\hline 35 & $39.90 \pm 1.48$ & - \\
\hline 36 & $49.91 \pm 1.02$ & $21.65 \pm 0.27$ \\
\hline 37 & $39.86 \pm 0.50$ & - \\
\hline 38 & $50.90 \pm 1.65$ & $25.62 \pm 0.39$ \\
\hline 39 & $9.18 \pm 0.41$ & - \\
\hline 40 & $3.84 \pm 0.21$ & - \\
\hline 41 & $2.40 \pm 0.53$ & - \\
\hline 42 & $59.15 \pm 0.93$ & $22.54 \pm 0.24$ \\
\hline 43 & $58.93 \pm 0.41$ & $24.01 \pm 0.33$ \\
\hline 44 & $4.84 \pm 0.19$ & - \\
\hline 45 & $10.48 \pm 0.40$ & - \\
\hline 46 & $8.11 \pm 0.20$ & - \\
\hline 47 & $9.63 \pm 0.90$ & - \\
\hline 48 & $9.83 \pm 1.06$ & - \\
\hline 50 & $6.93 \pm 0.16$ & - \\
\hline Chloroquine & $43.13 \pm 0.91$ & $25.04 \pm 0.26$ \\
\hline Dihydroartemisinin & $67.17 \pm 0.92$ & $18.04 \pm 0.21$ \\
\hline Mefloquine & $77.74 \pm 0.95$ & $15.78 \pm 0.12$ \\
\hline
\end{tabular}

Table 3 Classification of chromone compounds based upon the potency of antimalarial (AM) and $\beta$-hematin formation inhibitory ( $\beta$-HFI) activities.

\begin{tabular}{lccl}
\hline Group & AM & $\beta$-HFI & Compounds \\
\hline I & high & high & $3,4,23,24,27,36,38,43$ \\
II & high & low & $11,13,16,17,20,34,37$, \\
& & & $39,44-50$ \\
III & low & high & $25,26,28,42$ \\
IV & low & low & $1,5,12,14,15,18,19,22$, \\
& & & $29,31-33,35,40,41$ \\
\hline
\end{tabular}

Table 4 The stoichiometric ratio (chromone:heme) of compounds in Groups I and III.

\begin{tabular}{ll}
\hline Stoichiometric ratio & Compounds \\
\hline \multirow{2}{*}{$1: 1$} & Group I: 38 \\
& Group III: 28, 42 \\
& Dihydroartemisinin \\
\hline \multirow{2}{*}{$1: 2$} & Group I: 3, 4, 23, 24, 27, 43 \\
& Group III: 25, 26 \\
\hline $1: 3$ & Chloroquine, Mefloquine \\
\hline
\end{tabular}

ity study, these potent compounds belonged to 3unsubstituted chromones series. However, compounds in 3-substitued chromone series, 36, 38, 42, and $43\left(\mathrm{IC}_{50} 21.65,25.62,22.54\right.$, and $24.01 \mu \mathrm{M}$, respectively) were found to possess slightly higher activity than chloroquine.

Table 3 shows the classification of chromone compounds based upon the potency of antimalarial and $\beta$-hematin formation inhibitory activities. Compounds $3,4,23,24,27,36,38$, and 43 in Group I displayed highly potent antimalarial activity $\left(\mathrm{IC}_{50} 0.95-19.66 \mu \mathrm{M}\right)$ and $\beta$-hematin formation inhibitory activity ( $\left.\mathrm{IC}_{50} 1.41-30.56 \mu \mathrm{M}\right)$. In group II, compounds $11,13,16,17,20,34,37,39,44-$ 50 showed potent antimalarial activity $\left(\mathrm{IC}_{50} 3.82-\right.$ $14.69 \mu \mathrm{M})$ but they possessed low $\beta$-hematin formation inhibition (less than $45 \%$ inhibition). On the other hand, compounds 25, 26, 28, and 42 in Group III were potent $\beta$-hematin formation inhibitor $\left(\mathrm{IC}_{50} 2.30,2.54,3.69\right.$, and $24.01 \mu \mathrm{M}$, respectively) but weak as antimalarial drug (less than $40 \%$ inhibition). The rest of the compounds (i.e., 1, 5, 12, 14, $15,18,19,22,29,31-33,35,40$, and 41) in Group IV were inactive as antimalarial and showed low $\beta$ hematin formation inhibitory activity (less than $45 \%$ inhibition). 
Dihydroartemisinin

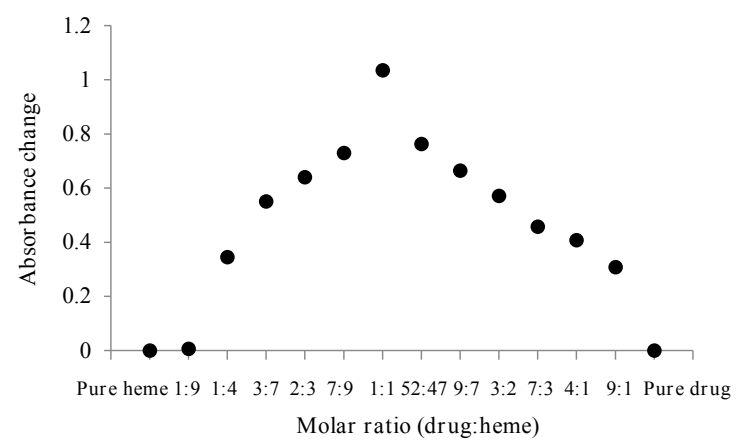

Chloroquine

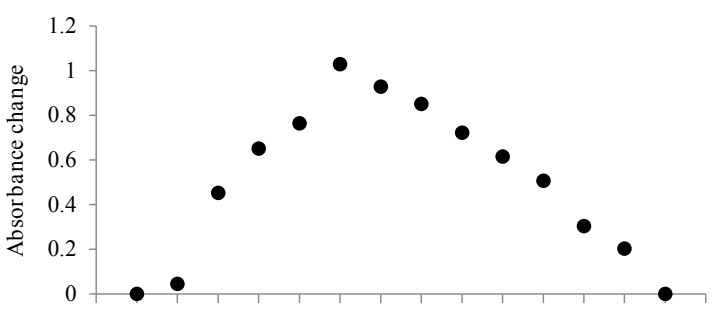

$\begin{array}{lllllll}\text { Pure heme 1:9 } & \text { 1:4 } & \text { 3:7 13:27 7:13 3:5 2:3 1:1 } & \text { 3:2 } & \text { 7:3 } & \text { 4:1 } & \text { 9:1 Pure drug }\end{array}$ Molar ratio (drug:heme)

Compound 25

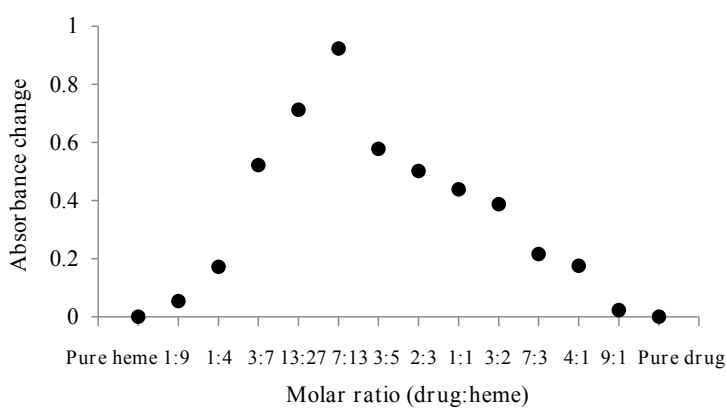

Compound 28

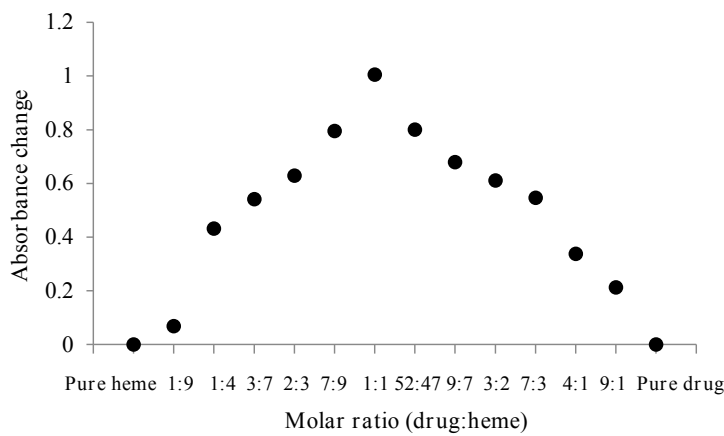

Compound 23

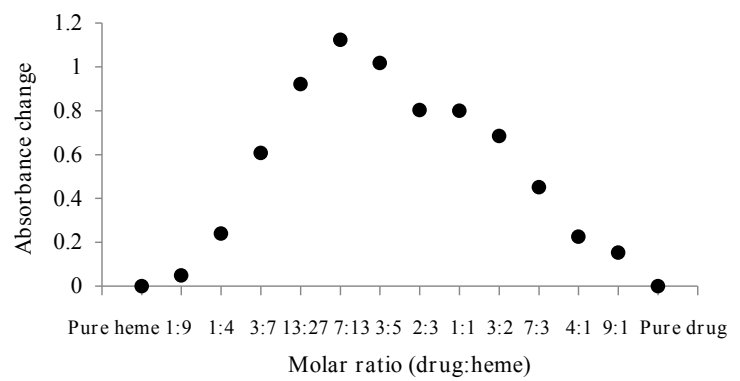

Compound 36

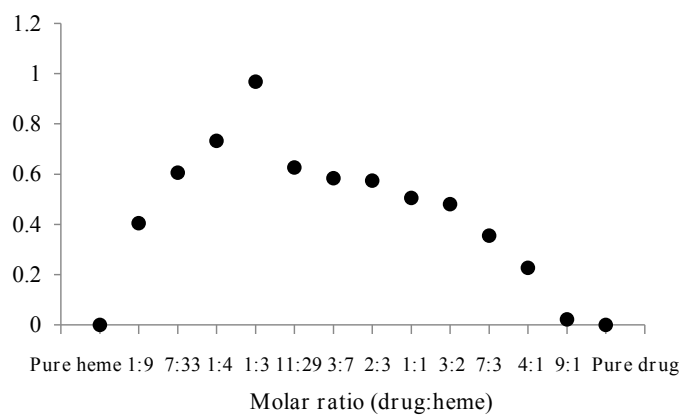

Fig. 2 Job's plots of dihydroartemisinin, chloroquine, and chromone compounds forming complex to heme with stoichiometric ratio of chromone:heme $=1: 1$ (dihydroartemisinin and compound 28), 1:2 (chloroquine and compounds 23 and 25), and 1:3 (compound 36).

\section{Drug-heme interaction}

Gorka et al have reported that the interactions between quinoline related drugs (including chloroquine) and heme leading to the inhibition of $\beta$ hematin formation which correlated with parasite growth inhibition ${ }^{11}$. In this study, the ability of chromone compounds to interact and form complex with heme was investigated by the continuous variation method (Job's plot) ${ }^{24}$. This method was based on the difference between UV spectral characteristics of free heme and drug-heme complex. A solution of hemin chloride showed a sharp peak at $400 \mathrm{~nm}$, indicating that free heme predominated under the in vitro condition used (40\% DMSO, sodium phosphate buffer at $\mathrm{pH}$ 6.0). The addition of potent chromone compounds (i.e., compounds 3 , 
$4,23,24,27,36,38$, and 43 in Group I and compounds $25,26,28$, and 42 in group III) resulted in decreasing of the absorption band of free heme, indicating that compounds formed complex with free heme. Plots between the difference in free heme absorbance at $400 \mathrm{~nm}$ versus the chromone:heme molar ratio were performed. Absorbance changes intensity were maximal when the molar fraction of compound 28 to heme was 1:1 (Fig. 2 for representative plots) indicating the stoichiometric ratio of chromone:heme $=1: 1$ as did dihydroartemisinin under the same experiment. The most potent compounds 23 (Group I) and 25 (Group III) showed the same stoichiometric ratio of $1: 2$ as chloroquine whereas compound 36 showed ratio of 1:3. Table 4 summarizes the stoichiometric ratios of compounds in Group I and III complexed with heme. These results indicated the ability of the chromone compounds to interact with free monomeric heme and confirmed the $\beta$-hematin formation inhibitory activity of the compounds.

\section{CONCLUSIONS}

The in vitro antimalarial activity against $P$. falciparum showed that most of the chromone compounds displayed moderate to high activity $\left(\mathrm{IC}_{50}\right.$ 0.95-19.66 $\mu \mathrm{M})$. $\beta$-Hematin formation inhibition assay has been performed to explore the preliminary mechanism of antimalarial activity of the studied compounds. Eight out of forty-two chromone compounds (compounds $3,4,23,24,27,36,38$, and 43) were found to exhibit high potency in both antimalarial and $\beta$-hematin formation assays. Compounds $23-28$ showed higher $\beta$-hematin formation inhibitory activity than chloroquine, dihydroartemisinin, and mefloquine. Job's plots revealed that compounds 23 and 24 strongly interacted with heme and formed stoichiometric ratio of chromone:heme $=1: 2$ same as chloroquine. Although further investigations are needed, the current data basically suggested that inhibiting $\beta$ hematin formation might be one of the mechanisms of antimalarial activity of compounds in chromone series.

Acknowledgements: The authors thank the Bioassay laboratory (BIOTEC) of the National Center of Genetic Engineering and Biotechnology (BIOTEC) for antimalarial activity assay.

\section{REFERENCES}

1. Banerjee R, Liu J, Beatty W, Pelosof L, Klemba M, Goldberg DE (2002) Four plasmepsins are active in the Plasmodium falciparum food vacuole, including a protease with an active-site histidine. Proc Natl Acad Sci USA 99, 990-995.

2. Greenwood BM, Bojang K, Whitty CJM, Targett GAT (2005) Malaria. Lancet 365, 1487-1498.

3. Cui L, Mharakurwa S, Ndiaye D, Rathod PK, Rosenthal PJ (2015) Antimalarial drug resistance: literature review and activities and findings of the ICEMR network. Am J Trop Med Hyg 93, 57-68.

4. Slater AF, Cerami A (1992) Inhibition by chloroquine of a novel haem polymerase enzyme activity in malaria trophozoites. Nature 355, 167-169.

5. Egan TJ (2002) Physico-chemical aspects of hemozoin (malaria pigment) structure and formation. $J$ Inorg Biochem 91, 19-26.

6. Slater AF, Swiggard WJ, Orton BR, Flitter WD, Goldberg DE, Cerami A, Henderson GB (1991) An ironcarboxylate bond links the heme units of malaria pigment. Proc Natl Acad Sci USA 88, 325-329.

7. Pagola S, Stephens PW, Bohle DS, Kosar AD, Madsen SK (2000) The structure of malaria pigment betahaematin. Nature 404, 307-310.

8. Vippagunta SR, Dorn A, Matile H, Bhattacharjee AK, Karle JM, Ellis WY, Ridley RG, Vennerstrom JL (1999) Structural specificity of chloroquine-hematin binding related to inhibition of hematin polymerization and parasite growth. J Med Chem 42, 4630-4639.

9. Egan TJ, Ncokazi KK (2005) Quinoline antimalarials decrease the rate of $\beta$-hematin formation. $J$ Inorg Biochem 99, 1532-1539.

10. Gorka AP, Sherlach KS, de Dios AC, Roepe PD (2013) Relative to quinine and quinidine, their 9-epimers exhibit decreased cytostatic activity and altered heme binding but similar cytocidal activity versus Plasmodium falciparum. Antimicrob Agents Chemother 57, 365-374.

11. Gorka AP, de Dios A, Roepe PD (2013) Quinoline drug-heme interactions and implications for antimalarial cytostatic versus cytocidal activities. $J$ Med Chem 56, 5231-5246.

12. Auparakkitanon S, Noonpakdee W, Ralph RK, Denny WA, Wilairat P (2003) Antimalarial 9-anilinoacridine compounds directed at hematin. Antimicrob Agents Chemother 47, 3708-3712.

13. Ignatushchenko MV, Winter RW, Bachinger HP, Hinrichs DJ, Riscoe MK (1997) Xanthones as antimalarial agents: studies of a possible mode of action. FEBS Lett 409, 67-73.

14. Xu Kelly J, Winter R, Riscoe M, Peyton DH (2001) A spectroscopic investigation of the binding interactions between 4,5-dihydroxyxanthone and heme. $J$ Inorg Biochem 86, 617-625.

15. Yenjai C, Prasanphen K, Daodee S, Wongpanich V, Kittakoop P (2004) Bioactive flavonoids from Kaempferia parviflora. Fitoterapia 75, 89-92.

16. de Monbrison F, Maitrejean M, Latour C, Bugnazet F, Peyron F, Barron D, Picot S (2006) In vitro anti- 
malarial activity of flavonoid derivatives dehydrosilybin and 8-(1;1)-DMA-kaempferide. Acta Trop 97, 102-107.

17. Lim SS, Kim HS, Lee DU (2007) In vitro antimalarial activity of flavonoids and chalcones. Bull Korean Chem Soc 28, 2495-2497.

18. Khaomek P, Ichino C, Ishiyama A, Sekiguchi H, Namatame M, Ruangrungsi N, Saifah E, Kiyohara H, et al (2008) In vitro antimalarial activity of prenylated flavonoids from Erythrina fusca. J Nat Med 62, 217-220.

19. Ungwitayatorn J, Wiwat C, Samee W, Nunthanavanit P, Phosrithong N (2011) Synthesis, in vitro evaluation, and docking studies of novel chromone derivatives as HIV-1 protease inhibitor. $J$ Mol Struct 1001, 152-161.

20. Lerdsirisuk P, Maicheen C, Ungwitayatorn J (2014)
Antimalarial activity of HIV-1 protease inhibitor in chromone series. Bioorg Chem 57, 142-147.

21. Trager W, Jensen JB (1976) Human malaria parasites in continuous culture. Science 193, 673-675.

22. Desjardins RE, Canfield CJ, Haynes JD, Chulay JD (1979) Quantitative assessment of antimalarial activity in vitro by a semiautomated microdilution technique. Antimicrob Agents Chemother 16, 710-718.

23. Baelmans R, Dehara E, Muñoz V, Sauvain M, Ginsburg H (2000) Experimental conditions for testing the inhibitory activity of chloroquine on the formation of $\beta$-hematin. Exp Parasitol 96, 243-248.

24. Renny JS, Tomasevich LL, Tallmadge EH, Collum DB (2013) Method of continuous variations: Applications of Job's plots to the study of molecular associations in organometallic chemistry. Angew Chem Int Ed Engl 52, 11998-12013. 